\title{
Impact of climate change on inundation hazard along the river Meuse
}

\author{
B. Dewals \\ Research group Hydraulics in Environmental and Civil Engineering (HECE), \\ University of Liege (ULg), Belgium \\ G. Drogue \\ Centre de Recherches en Géographie (CEGUM), Université de Lorraine, Metz, France
}

S. Erpicum, M. Pirotton \& P. Archambeau

Research group Hydraulics in Environmental and Civil Engineering (HECE), University of Liege (ULg), Belgium

\begin{abstract}
As a part of the effort to scientifically inform the development of the adaptation strategy for the Meuse basin, we detail hereafter the generation of integrated climate and hydrological scenarios for the whole basin. We also present the setup of a first coordinated hydraulic modelling from spring to mouth of the river Meuse. The latter has enabled to compute the range of change in inundation hazard under the "wet" transnational hydrological scenario for the time slices 2021-2050 and 2071-2100. A significantly higher impact of climate change has been found in the middle part of the Meuse basin, compared to the upper and the lower parts. These conclusions have been further confirmed by a refined analysis conducted for a $100 \mathrm{~km}$-long stretch of the river Meuse crossing the Belgian-Dutch border.
\end{abstract}

\section{INTRODUCTION}

Flooding is the most common natural hazard and third most damaging globally (Wilby and Keenan, 2012). Since flood risk is expected to further increase as a result of environmental changes, including climate change, adaptation strategies need to be developed to manage the risk affecting populations and goods.

In their review of flood mapping practices in Europe, Van Alphen et al. (2009) highlight the need for more uniform approaches in flood (risk) assessments and mapping since many European rivers are part of transboundary basins. Similarly, Becker et al. (2007) compared flood management factors in the German and Dutch parts of the Rhine basin and conclude on the need for more efficient transboundary flood management. They also suggest means to develop a common vision for future flood strategies and implement flood management issues. Van Pelt et al. (2011) showed that adequately capturing the transnational character of the river basins remains a challenging research question: whereas integrated analysis at the full river basin level, rather than within the boundaries of the riparian countries, would offer new adaptation opportunities, it will also meet many practical challenges.

Like many other basins in Europe, the Meuse basin is transnational. With a drainage surface of $35,000 \mathrm{~km}^{2}$, it covers parts of France, Belgium, The Netherlands, Germany as well as a small portion of Luxembourg. The Meuse is a rain-fed river with limited groundwater storage capacity to buffer precipitations. As a result, its discharge fluctuates considerably with seasons. For instance, measured flow rates in Liege may be as low as $20 \mathrm{~m}^{3} / \mathrm{s}$ during low flows, whereas they exceeded $3000 \mathrm{~m}^{3} / \mathrm{s}$ during winter 1993.

Since 2002, the countries of the Meuse basin have been cooperating through the International Meuse Commission (IMC) to coordinate the implementation of the Water Framework Directive (2000/60/EC) and, more recently, the EU Floods Directive (2007/60/EC). In the framework of the on-going AMICE project, a basin-wide coordinated strategy is being developed to cope with hydrological impacts of climate change, including floods and low flows.

However, a lack of knowledge remains concerning the influence of climate change on flood risk in the Meuse basin, specifically on inundation hazard (including flood discharges and inun- 
dation characteristics) which constitutes a crucial input for developing a coordinated adaptation strategy for the whole basin. Among others, Leander et al. (2008) evaluated the effect of climate change on flood discharge of the Meuse by using precipitation and temperature data from three regional climate model (RCM) experiments, driven by two different global circulation models (GCM). The HBV rainfall-runoff model was used for the control climate (1961-1990) and the SRES-scenario A2 (2071-2100). It was found that the changes in the flood discharges were highly sensitive to the driving GCM.

As the adaptation strategy to be developed for the Meuse basin is intended to be truly integrated at the level of the transboundary basin, it requires a significant degree of coordination and/or harmonization of the existing regional tools and methodologies for flood risk analysis, such as climate and hydrological scenarios, hydraulic modelling and impact modelling. In particular, existing hydrological scenarios were too heterogeneous and too sporadic to be used at the basin scale. Therefore, the AMICE project has contributed to coordinating and/or harmonizing the modelling tools and methodologies throughout the basin.

In this paper, we focus on the development of integrated climate and hydrological scenarios, as well as on the setup of coordinated hydraulic modelling for the whole Meuse and some tributaries.

\section{METHODOLOGY}

Evaluating the impact of climate change on inundation hazard requires that climate projections are downscaled to the relevant scales characterizing hydrological processes and inundation flows in the floodplains (Table 1). Therefore, this study involves three main steps, namely the development of integrated climate and hydrological scenarios (steps 1 and 2), as well as hydraulic modelling along river Meuse and some tributaries (step 3).

Table 1. Typical space and time scales in climate, hydrological and hydraulic modelling

\begin{tabular}{lll} 
& Space scale & Time scale \\
\hline Global Circulation Models & $\sim 10^{5} \mathrm{~m}$ & $\sim 10^{5} \mathrm{~s}$ \\
Regional Climate Models & $\sim 10^{4} \mathrm{~m}$ & $\sim 10^{5} \mathrm{~s}$ \\
$\begin{array}{l}\text { Rainfall-runoff models } \\
\text { (catchment-scale) }\end{array}$ & $10^{2}-10^{3} \mathrm{~m}$ & $10^{3}-10^{4} \mathrm{~s}$ \\
$\begin{array}{l}\text { Hydraulic and impact models } \\
\text { (river- and floodplain-scale) }\end{array}$ & $1-10 \mathrm{~m}$ & $10^{2}-10^{3} \mathrm{~s}$
\end{tabular}

\subsection{Integrated climate scenarios}

Following a review of climate experiments used within the Meuse basin, showing the lack of bias corrected climate simulations at the Meuse basin scale, the delta change approach was first applied to existing national climate scenarios. Next, common transnational climate scenarios with high resolution time series were derived (Drogue et al., 2010).

The greenhouse gases (GHG) emission scenarios commonly used in climate change studies have been developed by the Intergovernmental Panel on Climate Change (IPCC) since 1996 and they have been described in the Special Report on Emission Scenarios (SRES). For each group of scenarios, one scenario has been selected as a reference (A1B, A2, B1 and B2). These are the most widely used scenarios for GCM simulations and for impact studies of climate change.

Based on GCM /RCM simulations forced with IPCC SRES emission scenarios, each national meteorological institute has provided seasonal trends for the future climate ( $\Delta$ in $\%$ for rainfall change and in ${ }^{\circ} \mathrm{C}$ for air temperature variation in winter, spring, summer and autumn).

Although many existing climate change studies provide insights for the end of the century, decision makers also need information on the short and medium terms. Therefore, two time horizons were considered: 2021-2050 and 2071-2100. The 30 years span was used because climatological data are generally available for a 30 years long reference period. 


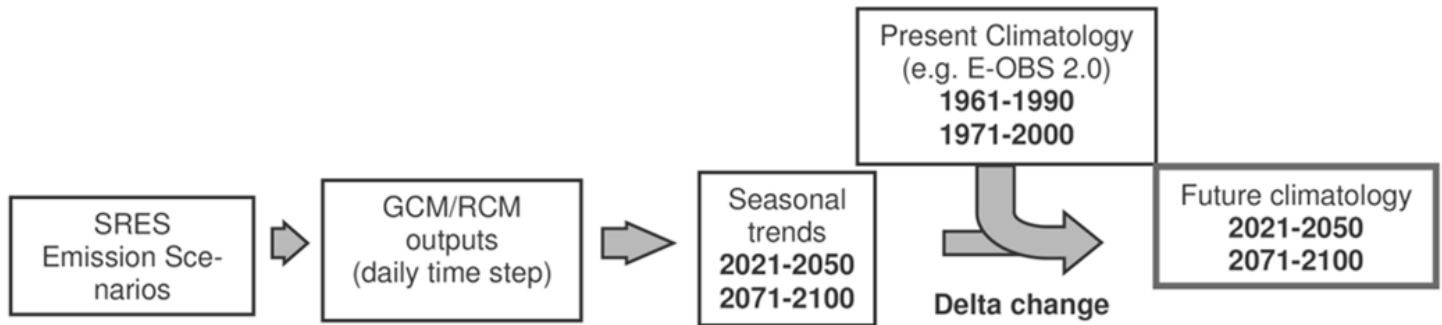

Figure 1. The delta change approach as carried out in the Amice project.

The climate of these two periods has been compared to a reference period (1971-2000). Monthly or even daily data series would have provided an even better insight, but these were not yet validated when the work started. The delta change approach has been used to modify the climate parameters on the reference period through seasonal perturbation factors (Figure 1).

All global circulation models agree that air temperature will increase in Europe in the coming decades. In contrast, rainfalls are either expected to increase or to decrease in the Meuse area, depending on the models. To account for such uncertainties, the delta change approach has been applied to create one "wet" and one "dry" climate scenarios for each period and for each national sub-basin. In between these two scenarios lies a wide range of possible futures.

Since the seasonal trends obtained for each national sub-basin presented significant heterogeneities, a transnational scenario was developed by weighting national trends according to the drainage area of each sub-basin. This enables to maintain downstream consistency of discharges, especially at national and regional borders.

\subsection{Integrated hydrological scenarios}

For nine selected gauging stations, rainfall-runoff modelling was conducted to estimate the evolution of flood and low-flow discharges during the $21^{\text {st }}$ century. No single rainfall-runoff model is available to cover the whole Meuse basin with a sufficient level of details. The different rainfall-runoff models used in each sub-basin are given in Table 2. These models compute river discharges using basically the same input climate data (air temperatures, potential evapotranspiration and precipitation) and some characteristics of the basin and river (slope, land cover, etc.).

Besides a control run (1971-2000 or 1961-1990), the two time horizons 2021-2050 and 20712100 were simulated. The considered gauging stations are located in four countries:

- four stations along the French part of the river Meuse: Saint-Mihiel, Stenay, Montcy-NotreDame and Chooz;

- one station at the Belgian-Dutch border: Sint Pieter;

- four stations on the Belgian and German right-side tributaries: Gendron (river Lesse), Chaudfontaine (river Vesdre), Stah (river Rur) and Goch (Niers triver).

In order to define the values of discharges for different return periods, a statistical distribution has been fitted to the observed and simulated discharge series. The sampling method of annual maximum discharges was used, as it is the most common method used to evaluate quantiles of flood discharges. In most cases, the parameters of the statistical distributions were estimated through the maximum-likelihood method. Different theoretical statistical distributions (Gumbel, Weibull, etc.) were used for calculating the quantiles of annual winter hourly maximum discharge value (e.g., $\mathrm{Qhx}_{100}$ ). For each gauging station, the theoretical statistical distribution was selected according to the fitting quality between observed and calculated quantiles.

Table 2. Rainfall-runoff models used in the different sub-basins of river Meuse.

\begin{tabular}{ll} 
Sub-basin & Model \\
\hline France & AGYR and GR4J \\
Belgium (Wallonia) & EPIC-Grid \\
Belgium (Flanders) & TOPModel and MIKE11 Maas \\
The Netherlands & HBV \\
Germany & NASIM and GR4J
\end{tabular}




\subsection{Coordinated hydraulic modelling}

Coordinated hydraulic modelling was first performed from spring to mouth of the river Meuse, based on exchanges of boundary conditions between the existing models in the different regions. Next, two very similar 2D unsteady models were applied to conduct a more refined analysis of a selected stretch of about $100 \mathrm{~km}$ crossing the Belgian-Dutch border.

\subsubsection{Coordinated modelling from spring to mouth of river Meuse}

Hydraulic models are available in each region of the Meuse basin. They are either commercial ones or academic codes. However, significant differences between those models have been identified, reflecting differences in the characteristics of the basin, including:

- in terms of spatial representation, the model range from fully one-dimensional, based on cross-sections even in the floodplains (e.g., in France), up to fully two-dimensional description based on laser altimetry and sonar bathymetry (e.g. in Wallonia);

- time description also differs between the models (either unsteady or run in steady mode).

Based on a detailed review of existing modelling procedures, a coordinated methodology for hydraulic modelling has been developed (Detrembleur et al., 2012). The methodology involves the following key aspects:

- consistency of bathymetry has been ensured across the borders, including latest dredging works; although the data in the different regions were not collected at the same period.

- regional hydrological time series and statistical analysis have been compared to derive consistent discharge values for a wide range of return periods.

- a coordinated procedure has been elaborated for running the hydraulic models.

Following this newly developed procedure, the hydraulic models from the different regions have been run in parallel but not coupled online. Nonetheless, consistent hydraulic results across the borders have been obtained in just two runs:

- in the first one, necessary boundary conditions have been deduced from extrapolation of measured stage-discharge relationships;

- in the second one, the boundary conditions have been refined if necessary, using the results of the first run of the neighbouring models.

This coordinated modelling methodology has enabled to conduct the first hydraulic simulation from spring to mouth of river Meuse. The modelling has been run for the 100-year flood in the base scenario (present situation), as well as for the "wet" hydrological scenario (section 2.2). The two aforementioned time horizons are also considered here: 2021-2050 and 2071-2100.

\subsubsection{Refined analysis}

The characteristics of the hydraulic models used in the different regions differ significantly. In particular, the model used in the Walloon part of the Meuse basin was fully two-dimensional, but was run in steady mode. In contrast, the model used in the Dutch part of the Meuse was onedimensional and unsteady.

Therefore, a refined analysis has been undertaken along a $100 \mathrm{~km}$ long transnational section of the Meuse, between Ampsin and Maaseik, using very similar models for the Walloon and the Dutch parts: WOLF 2D (Belgian part) and WAQUA (Dutch part), which are both 2D and run in unsteady mode. This has enabled to quantify the damping of the flood waves and to assess the relevance of using a steady model in this part of the Meuse basin.

Additionally to the peak discharge, the shape of the whole flood wave is necessary to prescribe the upstream boundary conditions of unsteady hydraulic simulations. The different methodologies to generate synthetic flood waves available in Wallonia, Flanders and the Netherlands were compared and tested to generate a 100-year synthetic flood wave at the Belgian-Dutch border. The Walloon methodology was selected due to the high degree of similarity between the obtained flood wave and the measured hydrograph during the 1993 flood, its return period being the closest to 100 years among available records. Using the Walloon methodology is also of particular relevance, since the selected methodology is dedicated to be applied to generate inflow flood waves mainly in Ampsin and for river Ourthe in Liege.

Consistently with the integrated hydrological scenarios, the whole flood waves were assumed to be increased by, respectively, $15 \%$ and 30\% for the time horizons 2021-2050 and 2071-2100. 


\section{RESULTS AND DISCUSSION}

\subsection{Integrated climate scenarios}

Under the wet transnational scenario (Figure 2), air temperatures are expected to increase by 1.3 ${ }^{\circ} \mathrm{C}$ to $2.9{ }^{\circ} \mathrm{C}$, with little difference between the seasons. Increases in air temperatures are higher for the dry scenario, especially in summer. According to the wet scenario, precipitations are expected to increase in winter $(+11 \%$ in $2021-2050$ and $+25 \%$ in $2071-2100)$ whereas, even under this scenario, precipitations are expected to decrease in summer. Under the dry scenario, precipitations tend mostly to decrease, or to remain unchanged.

In order to check the consistency of the approach, the results for the transnational scenarios were compared to the RCM simulations produced by the European FP5 PRUDENCE project (De Wit et al., 2007). Both results match relatively closely, which reinforces the methodology used.

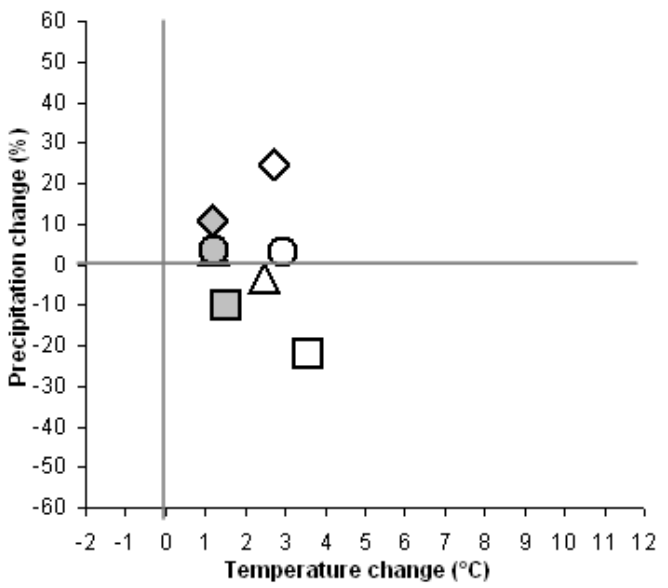

(a) Wet scenario

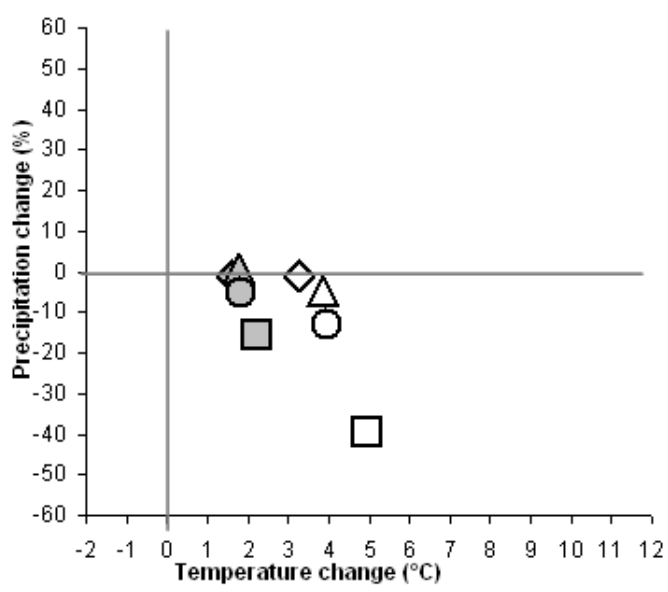

(b) Dry scenario

Figure 2. Seasonal trends in precipitation $(\%)$ and air temperature $\left({ }^{\circ} \mathrm{C}\right)$ for the transnational scenarios and for the two time slices (grey: 2021-2050 - white: 2071-2100; $\diamond=$ winter, $\triangle=$ spring, $\square=$ summer, $\mathrm{O}=$ autumn).

\subsection{Integrated hydrological scenarios}

To analyse the changes in flood discharges, the annual winter hourly maximum discharge, noted Qhx was selected as representative hydrological variable. The considered return periods are 2, 5, $10,25,50$ and 100, as well as 250 and 1250 for the lower part of the basin. The results presented here focus on the 100-year return period $\left(\mathrm{Qhx}_{100}\right)$.

In order to characterize the evolution of the flood discharges, a perturbation factor was calculated at the nine aforementioned gaugingstations for both considered time horizons (2021-2050 and 2071-2100) and for the wet, dry as well as national climate scenarios. The perturbation factor is defined as the ratio between the simulated values of the discharge for a given scenario and those simulated for the present climate. A value above 1 corresponds to an increase of the flood discharge value and vice-versa. Table 2 shows the perturbation factors obtained according to the transnational scenario for $\mathrm{Qhx}_{100}$ in the selected gauging stations located on the main course of river Meuse.

For the transnational climate scenario, the sign of the change in maximum discharge is logically homogeneous across the basin: an increase (decrease) in discharge is expected for the wet (dry) scenario. The range of change is more important for the end of the century.

Based on the results of Table 3 and discussions with a panel of experts and stakeholders in the Meuse basin, hydrological scenarios for the whole Meuse basin were defined (Drogue et al., 2010). The most extreme hydrological scenario considered for flood risk analysis was derived from the transnational wet climate scenario. In agreement with Table 3, it assumes an increase in $\mathrm{Qhx}_{100}$ values of $+15 \%$ for $2021-2050$ and $+30 \%$ for $2071-2100$. 
Table 3. Perturbation factors obtained for the hourly winter centennial flood peak $\left(\mathrm{Qhx}_{100}\right)$, wet and dry climate scenarios, at the gauging stations located along the main course of river Meuse.

\begin{tabular}{ccccccc}
$\begin{array}{c}\text { Time } \\
\text { horizon }\end{array}$ & Scenario & St-Mihiel & Stenay & Montcy & Chooz & St-Pieter \\
\hline \multirow{2}{*}{$2021-2050$} & Wet & 1.12 & 1.12 & 1.12 & 1.12 & 1.14 \\
& Dry & 0.96 & 0.96 & 0.96 & 0.96 & 0.95 \\
$2071-2100$ & Wet & 1.27 & 1.27 & 1.27 & 1.27 & 1.33 \\
& Dry & 0.89 & 0.89 & 0.89 & 0.89 & 0.91
\end{tabular}

\subsection{Changes in inundation hazard}

The results of hydraulic modelling results have been analysed at two complementary scales, namely the reach scale and the local scale (hotspots).

At the reach scale, the hydrological impacts of climate change have been evaluated in terms of their effects on hydrograph damping and peak discharges, water levels, extent of inundated areas and volume stored in the floodplains (Detrembleur et al., 2012). In particular, the integrated hydraulic modelling conducted has revealed a strong spatial pattern in the sensitivity of river stages with respect to changes in flood discharge (Figure 3): the influence of a similar change in flood discharge is found to be approximately twice stronger in the central part of the basin (between Sedan and Monsin) compared to the upper and lower parts of the basin, respectively upstream of Sedan and downstream of Monsin. This finding can be easily explained by considering the main characteristics of the Meuse basin: both the upper and the lower parts of the basin (including lowlands in The Netherlands) are characterised by relatively wide floodplains with large storage capacity; whereas, in the central part of the basin (Ardennes massif) the river valleys are steeper and narrower, leading to limited storage capacity in the floodplains. As a result, river stages are indeed expected to show a higher sensitivity in the central part of the basin. We also checked that this abrupt change in the sensitivity of water stages does not coincide with a change in the hydraulic models used. As it was not the case, we come to the conclusion that this finding is not affected by such kind of numerical artefact.

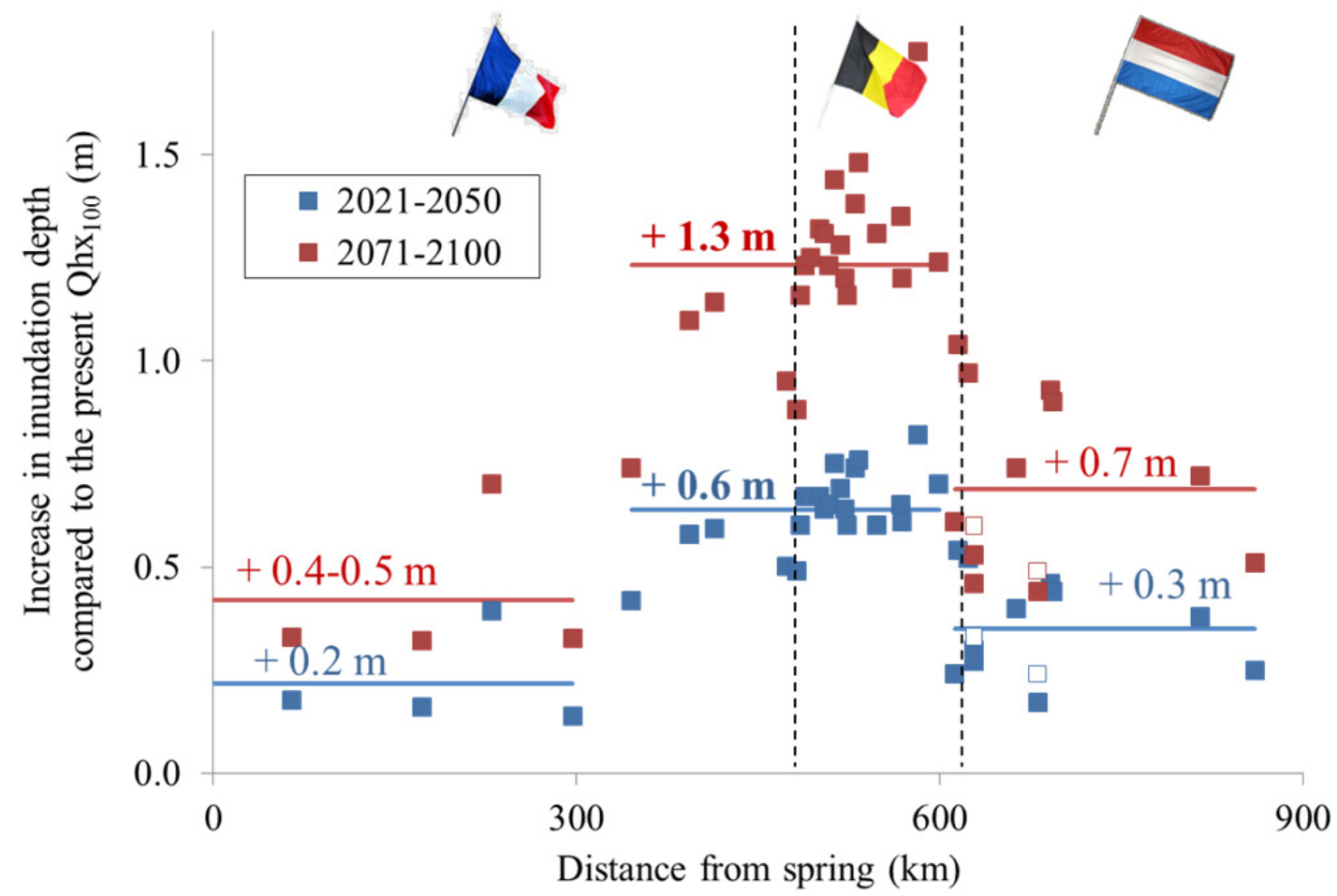

Figure 3. Change in flood levels compared to the present 100-year flood. 
Analysis of a hotspot in France (Charleville-Mézières) highlights that, although extra flooded areas due to climate change have been found generally limited in their extent, they may nevertheless lead to serious impacts when key assets are situated within the future flood-prone area (e.g., a town hall in which the crisis management headquarter is located). As shown in Figure 4, the hotspots in Wallonia reveal that existing flood defences of the main cities along river Meuse (Namur and Liege) may not be considered as "climate-proof". Indeed, although these cities are basically protected for present climate conditions, they would in contrast be exposed to huge flooding as a result of climate change. The common Flemish and Dutch hotspot (stretch of river Meuse along the border) emphasizes the importance of representing accurately protection structures (e.g., dikes) in the hydraulic modelling.

The refined unsteady $2 \mathrm{D}$ hydraulic simulations have shown that only a very limited damping of the flood waves is obtained along the simulated reaches (Dewals et al., 2013):

- for the present $\mathrm{Qhx}_{100}$, a maximum of $\sim 1 \%$ damping of the peak discharge in the Walloon part and another $\sim 1 \%$ damping for the Dutch part

- for $\mathrm{Qhx}_{100}+15 \%$, the damping of the peak discharge remains around $1 \%$ in the Walloon part, but reaches about 3\% in the Dutch part;

- for $\mathrm{Qhx}_{100}+30 \%$ the damping of the peak discharge is of maximum 3 to $4 \%$ both in Wallonia and in the Netherlands.

From the perspective of the variation in peak discharge, the study enables to conclude that using the Walloon model WOLF 2D in steady mode makes perfectly sense. Nonetheless, extensive overestimations by the steady model of the inundated extent and of the stored volume in the floodplains have been highlighted.

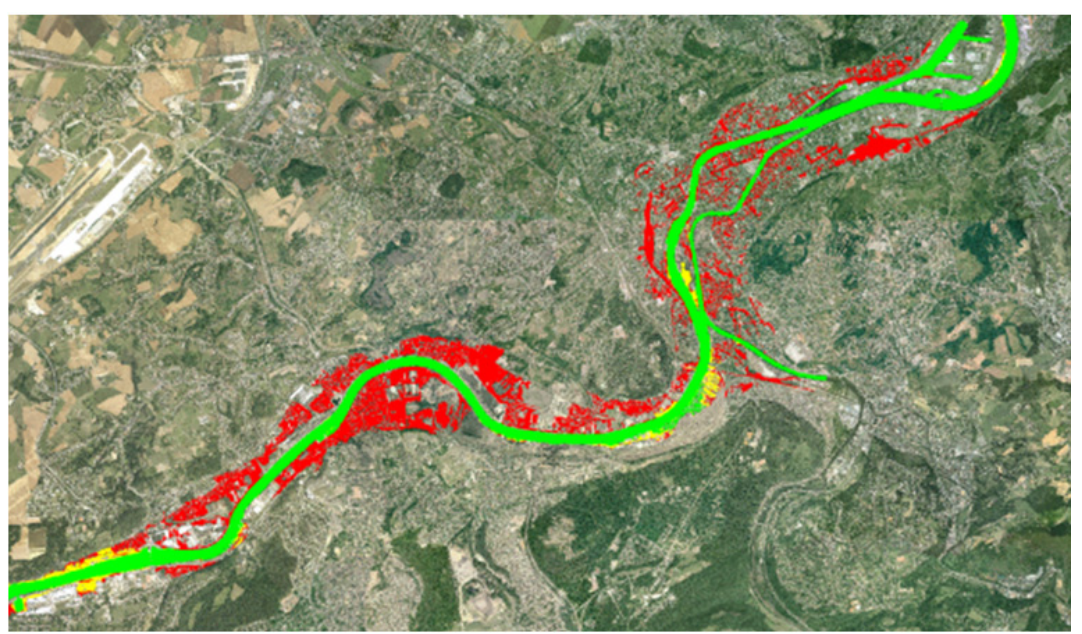

Figure 4. Inundation extent in the area of Liege for a 100-year flood in the present climate ( $\square$ ), additional extent for the 2021-2050 period (wet scenario) ( $\square$ ), additional extent for the 2071-2100 period (wet scenario) (ष). Hydraulic computations were performed with WOLF 2D in unsteady mode.

\section{CONCLUSION}

Integrated climate change scenarios for the Meuse river basin have been derived from a weighted-average of national and regional climate scenarios obtained by the delta change method. To take into account the uncertainties on future climate, a "wet" and a "dry" scenario have been defined for the time horizons 2021-2050 and 2071-2100. They were used to force different rainfall-runoff models, from which integrated hydrological scenarios were produced. Under the wet transnational scenario, flood discharges are expected to increase by, respectively, $15 \%$ (2021-2050) and 30\% (2071-2100).

Coordinated hydraulic modelling was conducted from spring to mouth of river Meuse. It has revealed a strong spatial pattern in the sensitivity of flood levels with respect to changes in flood discharge: the increase in flood levels is about twice higher in the central part of the basin compared to the upper and lower parts. The topographic characteristics of the valley explain this 
change, which does not result from a change in the model used. The hydraulic modelling has also provided the changes in inundation extent and volume stored in the floodplains.

To investigate the sensitivity of the results with respect to modelling assumptions differing from one region to the other, a refined analysis has been performed for a $100 \mathrm{~km}$ long section of river Meuse crossing the Belgian-Dutch border. Based on detailed 2D unsteady simulations, this analysis has confirmed the marginal damping of flood waves in this section of the Meuse and, consequently, the relevance of using steady simulations for inundation modelling in this area.

The results of this research also emphasize the need for more analysis concerning several key aspects. Only few SRES scenarios were considered and the integrated scenarios do not reflect the whole uncertainty range, especially a low probability/high impact climate scenario was not considered. More hydrological and hydraulic modelling will also be needed, such as to investigate the influence of landuse change in the catchment and in the floodplains, as well as to evaluate various adaptation measures (e.g., adapted spatial planning). The possible damping of flood waves in reaches upstream of Ampsin should be studied as well.

The 2D unsteady model set up so far constitutes a tool of primary interest, which is readily available to design and evaluate protection measures for future flood-prone areas such as Liege. It also constitutes a very valuable input for impact assessment and risk modelling (e.g., Ernst et al., 2010), as well as for the elaboration of the Meuse adaptation strategy.

\section{ACKNOWLEDGEMENTS}

This research was carried out in the framework of the Amice project funded under the NWE Interreg IVB Programme. The authors from ULg also gratefully acknowledge the "Service Public de Wallonie" (SPW) for the Digital Surface Model and the hydrological data.

\section{REFERENCES}

BECKER, G., AERTS, J. \& HUITEMA, D. 2007. Transboundary flood management in the Rhine basin: Challenges for improved cooperation. Water Science and Technology, 56, 125-135.

DE WIT, M. J. M., VAN DEN HURK, B., WARMERDAM, P. M. M., TORFS, P. J. J. F., ROULIN, E. \& VAN DEURSEN, W. P. A. 2007. Impact of climate change on low-flows in the river Meuse. Climatic Change, 82, 351-372.

DETREMBLEUR, S., DEWALS, B., FOURNIER, M., BECKER, B., GUILMIN, E., MOESKOPS, S., KUFELD, M., ARCHAMBEAU, P., DE KEIZER, O., PONTEGNIE, D., HUBER, N. P., VANNEUVILLE, W., BUITEVELD, H., SCHÜTTRUMPF, H. \& PIROTTON, M. 2012. Effects of climate change on river Meuse: hydraulic modelling from spring to mouth. Scientific report of the AMICE Project (WP1-Action 6).

DEWALS, B., ARCHAMBEAU, P., HUISMANS, Y., DE KEIZER, O., DETREMBLEUR, S., BUITEVELD, H. \& PIROTTON, M. 2013. Effects of climate change on river Meuse: hydraulic modelling from Ampsin to Maaseik. Scientific report of the AMICE Project (WP1-Action 6).

DROGUE, G., FOURNIER, M., BAUWENS, A., H., B., COMMEAUX, F., DEGRÉ, A., DE KEIZER, O., DETREMBLEUR, S., DEWALS, B., FRANÇOIS, D., GUILMIN, E., HAUSMANN, B., HISSEL, F., HUBER, N., LEBAUT, S., LOSSON, B., KUFELD, M., NACKEN, H., PIROTTON, M., PONTÉGNIE, D., SOHIER, C. \& VANNEUVILLE, W. 2010. Analysis of climate change, high-flows and low-flows scenarios on the Meuse basin. Scientific report of the AMICE Project (WP1-Action 3).

ERNST, J., DEWALS, B. J., DETREMBLEUR, S., ARCHAMBEAU, P., ERPICUM, S. \& PIROTTON, M. 2010. Micro-scale flood risk analysis based on detailed 2D hydraulic modelling and high resolution geographic data. Natural Hazards, 55, 181-209.

LEANDER, R., BUISHAND, T. A., VAN DEN HURK, B. J. J. M. \& DE WIT, M. J. M. 2008. Estimated changes in flood quantiles of the river Meuse from resampling of regional climate model output. Journal of Hydrology, 351, 331-343.

VAN ALPHEN, J., MARTINI, F., LOAT, R., SLOMP, R. \& PASSCHIER, R. 2009. Flood risk mapping in Europe, experiences and best practices. Journal of Flood Risk Management, 2, 285-292.

VAN PELT, S. C. \& SWART, R. J. 2011. Climate Change Risk Management in Transnational River Basins: The Rhine. Water Resources Management, 25, 3837-3861.

WILBY, R. L. \& KEENAN, R. 2012. Adapting to flood risk under climate change. Progress in Physical Geography, 36, 348-378. 